\title{
CATION SELECTIVITY OF VERTISOLS
}

\author{
Amer W. Abdul-Kareem \\ Soil Sciences and Water Resources Dept., College of Agriculture and Forestry, \\ Mosul University. Iraq \\ E-mail: amer-waddie@yahoo.com
}

\begin{abstract}
The effect of salinity and SAR on Gapon selectivity coefficient of two Vertisols, collected from Duhok Governorate in northern $\operatorname{Iraq}(\mathrm{Summel}$ and Zakho) classified taxonomically as (fine clay-smectitic-calcareous-cracked soils), were studied in a laboratory experiment. Twenty solutions, including five TEC levels $(5,10,20,50$ and $100 \mathrm{mmol}_{\mathbf{c}} \mathrm{l}^{-1}$ and four SAR levels $2.5,5.0,10$ and $25(\mathrm{mmol} .1)^{0.5}$ were synthesized to equilibrate the soil samples using chloride salts of sodium and calcium, magnesium . SAR of equilibrium solution decreased compared to equilibrating solution especially at high SAR and low electrolyte solutions. At low salt concentrations , the dissolution of $\mathrm{CaCO}_{3}$ and $\mathrm{Ca}$ bearing minerals causes a decrease in SAR of the equilibrium solution but their effect becomes less at high electrolyte concentrations . Exchangeable sodium increased with increase in SAR and TEC . Irrecpective of TEC , NaX increased by about 2.8-fold and 0.8 -fold and irrecpective of SAR, the increase was about 1.3-fold and 2.1-fold for Summel and Zakho sites respectively. An increase in ESP was observed when correction for anion exclusion was calculated especially at higher TEC level. All relationships between ESR and SAR were significant for each salinity level and when the treatments were handled as a composite data. The values of Gapon constant were in the range of (0.0057-0.0259) and $(0.0155-0.0425)(\mathrm{mmol} .1)^{-0.5}$ and Correction for anion exclusion caused an increase by about $18 \%$ and $11 \%$ for Summel and Zakho sites respectively compared to not corrected samples .
\end{abstract}

Keywords: Selectivity, Vertisols, Gapon coefficient, Anion repulsion, TEC.

Received: 21/2/2013, Accepted: 24/6/2013.

\section{INTRODUCTION}

Cation selectivity is the measurement of the relative affinity of surfaces for different cations. Theoretically, it depends on both the properties of surface functional groups and the adsorbed cations, with water playing an intermediary role (Xu and Harsh ,1990). Knowledge of the factors influencing cation selectivity is fundamental to an understanding of processes such as cation leaching, fertilizer-soil interactions, nutrient supply to plants and reclamation of salt-affected soils (Curtin etal. 1998). Many theoretical exchange equations have been developed and reported in the literature to describe the equilibrium distribution between exchangeable and soluble cations . Accordingly, numerous cation exchange selectivity coefficients have been determined for different soils to predict cation composition at exchange sites (Sharma etal.1988). The Gapon equation is most often used to describe $\mathrm{Na}-\mathrm{Ca}$ exchange in soil systems (Gapon,1933) . A modification of Gapon's equation (U.S. Salinity Laboratory Staff, 1954) permitted its extension to three cation systems by assuming that the divalent cations $\mathrm{Ca}^{2+}$ and $\mathrm{Mg}^{2+}$ have equivalent cation exchange 
properties. Vertisols occur in almost every major climatic zone of the world with their distinctive properties such as shrinking and cracking when dry and swelling when wet are some of the main features affecting their use and management (Ahmad and Mermut,1996). Therefore, mismanagement of irrigation on poorly drained Vertisols under semi-arid conditions could lead to waterlogging and soil Salinization (Jutzi etal. 1988) . Prevention of soil Salinization is of strategic importance, since a salinized Vertisols by faulty irrigation present an extremely difficult prospect to ameliorate because uniform leaching will not take place due to the water transmitting characteristic of the soil (Hashim,2011). To the irrigation planner , the understanding of exchange equilibria is important in predicting changes in exchangeable cation properties caused by the use of a given water for irrigation. The present study was carried out on selected Vertisols from Duhok Governorate in northern Iraq to establish the nature of equilibria involving $\mathrm{Na}^{+}$with $\mathrm{Ca}^{2+}$ and $\mathrm{Mg}^{2+}$ and obtain Gapon constants to predict cation exchange properties of these soils .

\section{MATERIALS AND METHODS}

Two sites representing different locations in the north of Iraq (Summel, Soil-1 and Zakho, Soil-2 of Duhok Governorate) were selected depending in changes in width and depth of cracks (Fayadh,2007). They were classified taxonomically as (Fin Clay, Smectitic, Superactive, Calcareous, thermic, Cracked, Chromic Haploxerert) (Soil Survey Staff, 2006). Soil samples were collected at each site from $0-10 \mathrm{~cm}$ depth, dried in air, passed through a sieve of $2 \mathrm{~mm}$. Basic physico-chemical properties are presented in Table (1). Dry soil samples were equilibrated with different quality waters encompassing four levels of sodium adsorption ratio (SAR) viz. 2.5, 5, 10 and 25 (mmol.1) ${ }^{\mathbf{0 . 5}}$ and five levels of total electrolyte concentrations (TEC) viz.5,10, 20, 50 and 100 mmol $_{\mathbf{c}} .1$. Pure chloride salts of calcium, magnesium and sodium were used to prepare different water quality.

Table (1): Some chemical and physical properties of the studied soils

\begin{tabular}{|c|c|c|c|}
\hline \multicolumn{2}{|c|}{ Soil properties } & Summel & Zakho \\
\hline \multicolumn{2}{|c|}{$\mathrm{pH}$} & 7.79 & 7.74 \\
\hline \multicolumn{2}{|c|}{$\mathrm{EC}\left(\mathrm{dS} \cdot \mathrm{m}^{-1}\right)$} & 0.56 & 0.57 \\
\hline $\mathrm{CaCO}_{3}$ equivalent & \multirow{5}{*}{$\mathrm{gm} \cdot \mathrm{kg}^{-1}$} & 156.4 & 225.5 \\
\hline Organic matter & & 14.93 & 12.95 \\
\hline Sand & & 25.0 & 125.0 \\
\hline Silt & & 310.0 & 255.0 \\
\hline Clay & & 665.0 & 620.0 \\
\hline \multicolumn{2}{|c|}{ Texture } & Clayey & Clayey \\
\hline \multicolumn{2}{|c|}{$\mathrm{CEC}\left(\mathrm{cmol}_{\mathrm{c}} \cdot \mathrm{kg}^{-1}\right)$} & 37.01 & 31.58 \\
\hline
\end{tabular}

Procedure outlined by Jurinak et al . (1984) was followed for soil sample equilibration. In $50 \mathrm{ml}$ centrifuge tubes, $4 \mathrm{~g}$ of sieved soil was taken and $30 \mathrm{ml}$ of a given quality water was added, shaken for $15 \mathrm{~min}$. and centrifuged. This procedure was repeated three times and only the final equilibrium solution was analyzed for $\mathrm{Na}^{+}$, $\mathrm{Ca}^{2+}, \mathrm{Mg}^{2+}$ and $\mathrm{CI}^{-}$by methods outlined by Tandon (1999) with three replicates for 
each soil and water quality. After decanting, the tubes plus samples were weighed . The solution weight was determined by differences and the solution volume by dividing the density of the solution which was calculated by weighing a known volume of the solution. From these data, the final solution SAR and ionic concentration values were calculated for each water quality. The samples were then extracted three times with $30 \mathrm{ml}$ solution of $1 \mathrm{~N} \mathrm{NH}_{4} \mathrm{OAC}$ of $\mathrm{pH} 8.6$ and volume was made up to $100 \mathrm{ml}$ and extracts were analyzed for the total $\mathrm{Na}^{+}$and $\mathrm{CI}^{-}$ions. The method used to calculate the exchangeable sodium $\mathrm{NaX}$ and exchangeable calcium and magnesium $(\mathrm{Ca}+\mathrm{Mg})_{0.5} \mathrm{X}$ was based on the ion excess concept applied to the charged interface which takes into account the negative adsorption of anions at the interface as outlined by Chaudhari and Somawanshi (2002). The NaX was calculated as : $\mathrm{NaX}=\mathrm{T}_{\mathbf{N a}}-\theta \mathrm{C}_{\mathbf{O N a}}$

Where $\mathrm{T}_{\mathrm{Na}}$ is the total $\mathrm{Na}^{+}$content $\left(\mathrm{cmol} \cdot \mathrm{kg}^{-1}\right)$ obtained by extracting the sample with $1 \mathrm{~N} \mathrm{NH} \mathrm{NHAC}_{4} \mathrm{OA}$ solution of $\mathrm{pH} 8.6$ and $\theta \mathrm{Co}_{\mathrm{Na}}$ in $\mathrm{cmol}^{3} \mathrm{~kg}^{-1}$ is the soluble sodium content where $\theta$ stands for water content in $\mathrm{cm}^{3} / 100 \mathrm{~g}$ and $\mathrm{Co}_{\mathrm{Na}}$ is the equilibrium concentration of $\mathrm{Na}^{+}$in $\mathrm{mmol}_{\mathbf{c}} \cdot \mathrm{cm}^{3}$. The term $(\mathrm{Ca}+\mathrm{Mg})_{0.5} \mathrm{X}$ was calculated as :

$$
(\mathrm{Ca}+\mathrm{Mg})_{0.5} \mathrm{X}=\mathrm{CEC}-\mathrm{NaX}-\mathrm{V}_{\text {an }}
$$

where CEC is the cation exchange capacity in cmolc. $\mathrm{kg}^{-1}$ and $\mathrm{V}_{\text {an }}$ is the anion exclusion term that account for the anions being repelled from the region adjacent to the negatively charged clay surface, it is a positive number and is calculated using the chloride ion as : $\mathbf{V}_{\mathbf{C I}}=\theta \mathbf{C}_{\mathbf{O C I}}-\mathrm{T}_{\mathbf{C I}}$

where terms were previously described. The ESR and ESP were computed as

$$
\mathrm{ESR} \frac{\mathrm{NaX}}{(\mathrm{Ca}+\mathrm{Mg})_{0.5} \mathrm{X}}=\frac{\mathrm{NaX}}{\mathrm{CEC}-\mathrm{NaX}-\mathrm{V}_{\text {an }}} \quad \mathrm{ESP} \frac{\mathrm{ESR}}{1+\mathrm{ESR}} \times 100
$$

\section{RESULTS AND DISCUSSION}

1.SAR of equilibrium solution: The data presented in table 3 and 4 showed that the $\mathrm{SAR}$ of equilibrium solution $\left(\mathrm{SAR}_{\mathrm{eq}}\right)$ decreased compared to the equilibrating solution $\left(\mathrm{SAR}_{\mathbf{i w}}\right)$ especially at low electrolyte concentration and high SAR. The difference between the two parameters widened with increasing $\mathrm{SAR}_{\mathbf{i w}}$. The maximum differences was observed with maximum $\mathrm{SAR}_{\mathbf{i w}}$, i.e. $25(\mathrm{mmol.1}){ }^{\mathbf{0 . 5}}$ at all TEC levels and soils being 75.2, 60.7, 49.4,43.6 and 37\% for Soil-1 and 88.0, 83.0 , 78.0 , 69.6 and $62.7 \%$ for Soil-2 at 5, $10,20,50$ and 100 mmol $_{\mathbf{c}} .^{-1}$ respectively. Among the studied soils, differences were perceptible at all TEC levels in the order : Soil-1 > Soil-2. At low electrolyte concentration, high final SAR values were not attained because the dissolution of $\mathrm{CaCO}_{3}$ and $\mathrm{Ca}$ primary minerals added sufficient calcium and magnesium to lower the initial SAR and more at Soil-2 due to the higher percentage of calcium carbonate (table1), but at higher levels, the difference between $\mathrm{SAR}_{\mathbf{e q}}$ and $\mathrm{SAR}_{\mathbf{i w}}$ decreased especially at Soil-1, because the salinity treatment retard the impact of mineral dissolution because of common ion effect . Jurinak etal., (1984), Chaudhari and Somawanshi (2002) and Frenkel and Alperovitch (1984) reported similar results. 
Table (2): Cation exchange characteristics of soil at Summel site.

\begin{tabular}{|c|c|c|c|c|c|c|c|c|}
\hline \multirow{2}{*}{$\begin{array}{c}\text { TEC } \\
\operatorname{mmol}_{\mathrm{c}} / 1\end{array}$} & $\mathrm{SAR}_{\mathrm{iw}}$ & $\mathrm{SAR}_{\mathrm{eq}}$ & \multirow{2}{*}{$\frac{\mathrm{NaX}}{\mathrm{cmol}_{\mathrm{c}} \cdot \mathrm{kg}^{-1}}$} & \multirow{2}{*}{ ESR } & $\mathrm{ESP}^{1}$ & ESP & $\mathrm{K}_{\mathrm{G}}^{1}$ & $\mathrm{~K}_{\mathrm{G}}$ \\
\hline & \multicolumn{2}{|c|}{$(\mathrm{mmol} .1)^{0.5}$} & & & \multicolumn{2}{|c|}{$\%$} & \multicolumn{2}{|c|}{$(\mathrm{mmol} / \mathrm{l})^{-0.5}$} \\
\hline \multirow{4}{*}{5} & 2.5 & 0.67 & 0.631 & 0.0174 & 1.710 & 1.701 & 0.0259 & 0.0259 \\
\hline & 5.0 & 2.53 & 1.124 & 0.0313 & 3.035 & 3.035 & 0.0124 & 0.0124 \\
\hline & 10 & 4.13 & 1.528 & 0.0431 & 4.132 & 4.131 & 0.0105 & 0.0105 \\
\hline & 25 & 6.19 & 1.639 & 0.0463 & 4.425 & 4.425 & 0.0075 & 0.0075 \\
\hline \multirow{4}{*}{10} & 2.5 & 0.95 & 0.842 & 0.0233 & 2.277 & 2.277 & 0.0245 & 0.0245 \\
\hline & 5.0 & 3.28 & 1.107 & 0.0310 & 3.010 & 2.988 & 0.0095 & 0.0094 \\
\hline & 10 & 6.81 & 1.782 & 0.0510 & 4.853 & 4.816 & 0.0075 & 0.0074 \\
\hline & 25 & 9.83 & 2.033 & 0.0598 & 5.643 & 4.816 & 0.0061 & 0.0059 \\
\hline \multirow{4}{*}{20} & 2.5 & 2.44 & 0.892 & 0.0252 & 2.458 & 2.410 & 0.0103 & 0.0101 \\
\hline & 5.0 & 3.61 & 1.185 & 0.0338 & 3.269 & 3.204 & 0.0094 & 0.0092 \\
\hline & 10 & 6.91 & 2.069 & 0.0597 & 5.634 & 5.589 & 0.0086 & 0.0085 \\
\hline & 25 & 12.65 & 2.361 & 0.0744 & 6.925 & 6.376 & 0.0059 & 0.0054 \\
\hline \multirow{4}{*}{50} & 2.5 & 2.87 & 0.631 & 0.0186 & 1.826 & 1.701 & 0.0065 & 0.0060 \\
\hline & 5.0 & 3.54 & 1.139 & 0.0342 & 3.307 & 3.082 & 0.0096 & 0.0089 \\
\hline & 10 & 8.27 & 2.353 & 0.0690 & 6.455 & 6.358 & 0.0083 & 0.0082 \\
\hline & 25 & 14.11 & 2.568 & 0.0807 & 7.467 & 6.942 & 0.0057 & 0.0053 \\
\hline \multirow{4}{*}{100} & 2.5 & 3.34 & 0.852 & 0.0282 & 2.743 & 2.306 & 0.0087 & 0.0073 \\
\hline & 5.0 & 5.28 & 1.096 & 0.0372 & 3.587 & 2.959 & 0.0072 & 0.0059 \\
\hline & 10 & 8.98 & 2.085 & 0.0726 & 6.769 & 5.634 & 0.0081 & 0.0067 \\
\hline & 25 & 15.76 & 2.607 & 0.0924 & 8.458 & 7.046 & 0.0058 & 0.0048 \\
\hline
\end{tabular}

SAR $_{\text {iw }}=$ SAR of equilibrating solution $\left(\mathrm{mmol}^{0}\right)^{0.5}$. SAR ${ }_{\mathrm{eq}}$ of equilibrium solution $\cdot \mathrm{NaX}=$ exchangeable sodium $\mathrm{cmol}_{+} \cdot \mathrm{kg}^{-1}$. $\mathbf{E S P}^{1}=\mathrm{ESP}$ corrected for anion exclusion $\cdot \mathrm{K}_{\mathrm{G}}^{1}=\mathrm{Gapon}$ constant corrected for anion exclusion in $(\mathrm{mmol} / \mathrm{l})^{-0.5}$.

2. Exchangeable sodium (ESR): The data obtained for exchangeable sodium presented in tables 3 and 4 showed that for the same level of TEC, exchangeable sodium values increased with increase in SAR from $2.5-25(\mathrm{mmol} .1)^{0.5}$ for all the soils with an average of 45 and $65 \%$ for Soil-2 and Soil-2 respectively. Increase in TEC also increased the $\mathrm{NaX}$. In order to assess the individual contribution of TEC and $\mathrm{SAR}, \mathrm{NaX}$ was calculated irrespective of these variables separately . Irrespective of TEC , NaX increased by about 2.8-fold and 0.8-fold when SAR was increased from $2.5(\mathrm{mmol} .1)^{0.5}$ to 25 and irrespective of SAR, the increase was about 1.3 -fold and about 2.1-fold when TEC was increased from 5 to 100 mmol $_{\mathrm{c}} \mathrm{l}^{-1}$ for Soil-1 and Soil-2 respectively, though the SAR and TEC of equilibrating solution were increased by 10 and 20 -fold, respectively .The results indicated that $\mathrm{SAR}_{\mathrm{iw}}$ had more of an effect on $\mathrm{NaX}$ than TEC at Soil-1 and their interaction was positive in increasing the sodicity hazard of soils. These results are in agreement with Paliwal and Gandhi(1976), Ponnia etal.(1984) and Chaudhari and Somawanshi(2002) . In Soil-2, increasing ionic strength at a fixed SAR caused an increase in Na-saturation of soil exchange complex . These results are apparently in contradiction to the theory of diffuse double layer which predicts a decrease in the fractional saturation of $\mathrm{NaX}$ with increase in TEC at a fixed SAR. The studied soils are calcareous with small amounts of gypsum and 
despite their equilibration with chloride salts of $\mathrm{Na}^{+}, \mathrm{Ca}^{+2}$ and $\mathrm{Mg}^{+2}$, it seems that with the increase in TEC at a fixed SAR, the concentration of $\mathrm{Ca}^{+2}$ was also increased which resulted in an increase in the amounts of ion pairs mostly with $\mathrm{HCO}_{3}$ in the equilibrium solution. This ultimately would have lead to an increase in Na-saturation of soil exchange complex ( Kachoui et al., 1994 and Kopittke et al., 2006).

Table (3): Cation exchange characteristics of soil at Zakho site.

\begin{tabular}{|c|c|c|c|c|c|c|c|c|}
\hline \multirow{2}{*}{$\begin{array}{c}\text { TEC } \\
\operatorname{mmol}_{\mathrm{c}} / 1\end{array}$} & $\mathrm{SAR}_{\mathrm{iw}}$ & $\mathrm{SAR}_{\mathrm{eq}}$ & $\mathrm{NaX}$ & \multirow{2}{*}{ ESR } & ESP & $\mathrm{ESP}^{1}$ & $\mathrm{~K}_{\mathrm{G}}^{1}$ & $\mathrm{~K}_{\mathrm{G}}$ \\
\hline & \multicolumn{2}{|c|}{$(\mathrm{mmol} .1)^{0.5}$} & $\mathrm{cmol}_{\mathrm{c}} \cdot \mathrm{kg}^{-1}$ & & \multicolumn{2}{|c|}{$\%$} & \multicolumn{2}{|c|}{$(\mathrm{mmol} / \mathrm{l})^{-0.5}$} \\
\hline \multirow{4}{*}{5} & 2.5 & 0.49 & 0.766 & 0.0249 & 2.429 & 2.429 & 0.0508 & 0.0508 \\
\hline & 5.0 & 2.03 & 1.214 & 0.0399 & 3.844 & 3.844 & 0.0197 & 0.0197 \\
\hline & 10 & 2.34 & 1.267 & 0.0418 & 4.012 & 4.012 & 0.0179 & 0.0179 \\
\hline & 25 & 3.04 & 1.413 & 0.0468 & 4.471 & 4.471 & 0.0154 & 0.0154 \\
\hline \multirow{4}{*}{10} & 2.5 & 0.95 & 1.016 & 0.0335 & 3.217 & 3.241 & 0.0425 & 0.0353 \\
\hline & 5.0 & 2.17 & 1.587 & 0.0534 & 5.027 & 5.069 & 0.0246 & 0.0244 \\
\hline & 10 & 2.61 & 1.673 & 0.0568 & 5.294 & 5.375 & 0.0218 & 0.0214 \\
\hline & 25 & 4.35 & 2.006 & 0.0679 & 6.349 & 6.358 & 0.0156 & 0.0156 \\
\hline \multirow{4}{*}{20} & 2.5 & 1.32 & 1.307 & 0.0442 & 4.141 & 4.233 & 0.0336 & 0.0327 \\
\hline & 5.0 & 2.53 & 1.811 & 0.0629 & 5.732 & 5.918 & 0.0249 & 0.0240 \\
\hline & 10 & 4.42 & 2.275 & 0.0806 & 7.201 & 7.459 & 0.0183 & 0.0176 \\
\hline & 25 & 5.51 & 2.302 & 0.0813 & 7.287 & 7.519 & 0.0148 & 0.0143 \\
\hline \multirow{4}{*}{50} & 2.5 & 1.63 & 1.589 & 0.0582 & 5.029 & 5.499 & 0.0436 & 0.0325 \\
\hline & 5.0 & 2.45 & 1.913 & 0.0710 & 6.059 & 6.629 & 0.0289 & 0.0263 \\
\hline & 10 & 4.32 & 2.375 & 0.0909 & 7.519 & 8.333 & 0.0211 & 0.0188 \\
\hline & 25 & 7.59 & 3.072 & 0.1180 & 9.731 & 10.55 & 0.0155 & 0.0142 \\
\hline \multirow{4}{*}{100} & 2.5 & 1.76 & 1.865 & 0.0769 & 5.851 & 7.141 & 0.0437 & 0.0353 \\
\hline & 5.0 & 3.03 & 2.326 & 0.0981 & 7.365 & 8.934 & 0.0324 & 0.0263 \\
\hline & 10 & 5.65 & 2.461 & 0.1038 & 7.792 & 9.404 & 0.0184 & 0.0149 \\
\hline & 25 & 9.33 & 3.236 & 0.1478 & 10.25 & 12.88 & 0.0158 & 0.0122 \\
\hline
\end{tabular}

$\mathrm{SAR}_{\mathrm{iw}}=\mathrm{SAR}$ of equilibrating solution $(\mathrm{mmol.l})^{0.5} . \mathrm{SAR}_{\mathrm{eq}}$ of equilibrium solution $. \mathrm{NaX}=$ exchangeable sodium $\mathrm{cmol}_{+} \cdot \mathrm{kg}^{-1}$. $\mathrm{ESP}^{1}=\mathrm{ESP}$ corrected for anion exclusion $. \mathrm{K}_{\mathrm{G}}{ }=$ Gapon constant corrected for anion exclusion in $(\mathrm{mmol} / \mathrm{l})^{-0.5}$.

3. Exchangeable sodium percentage (ESP) : Data presented in tables 2 and 3 revealed that the ESP increased with increasing SAR and TEC of equilibrating solutions . Irrespective of TEC, the ESP increased from 2.1 to 5.9 and from 4.1 to 7.6 in Soil-1 and Soil-2 respectively when SAR was increased from 2.5 to 25 . (mmol.l) ${ }^{0.5}$ Similarly, increase in TEC from 5 to $100 \mathrm{mmol}_{\mathrm{c}}{ }^{-1}$ increased ESP from 3.3 to 4.5 and 3.69 to 7.8 for the same sequence above when considered irrespective of SAR . It seems that the lowered CEC and higher exchangeable sodium of Soil-2 are the main reasons for higher ESP.. Additive effects of 100 mmol $_{\mathrm{c}} \mathrm{l}^{-1}$ total electrolyte concentration and $25 \mathrm{mmol} / \mathrm{l}^{0.5}$ sodium adsorption ratio recorded the highest level of ESP (12.88) in Soil-2 compared with 7.05 in Soil-2 . An increase in ESP was observed when correction for anion exclusion was calculated especially at higher TEC level and more so in Soil-2 (from 4.5 to 8.4 when SAR was increased from 2.5 to 25 
$(\text { mmol.l })^{0.5}$ and from 3.7 to 9.6 when TEC was increased from 5 to $100 \mathrm{mmol}_{\mathrm{c}} \mathrm{l}^{-1}$. However, at lower TEC level $\left(5 \mathrm{mmol}_{\mathrm{c}} \mathrm{l}^{-1}\right)$, such effect was not noticed at both sites. It is clear that for chloride rich waters anion exclusion play a significant role and should be corrected for a precise assessment of soil sodicity as was emphasized by Jurinak etal.(1984), Amrhein and Suarez (1991) and Chaudhari and Somaawanshi (2002) .

4- ESR-SAR relationship and Gapon constant (KG) : The regression of ESR on SAR presented in table 4 showed a significant regression coefficient when each level of salinity is statistically analyzed and when the treatments were handled as a composite data set and which indicate that the Gapon relationship is valid. The data revealed that correcting for anion exclusion increased $\mathrm{R}^{2}$ values . Data obtained on Gapon selectivity coefficient are presented in tables 1 and 2. The values of Gapon constant were in the range of $(0.0057-0.0259)$ and $(0.0155-0.0425)(\mathrm{mmol} / \mathrm{l})^{-0.5}$ in Soil-1 and 2 respectively. They decreased with increasing salinity (TEC) and SAR at soil-1 which suggests an apparent increasing preference for $\mathrm{Ca}^{2+}$ and $\mathrm{Mg}^{2+}$ by the exchange phase(lower KG values). The values of Soil-2 showed the same trend with increasing SAR but there mean were almost constant with increasing salinity and a comparison of data on KG revealed that Soil-2 showed higher values compared to Soil-1 at all interaction of TEC x SAR and could be caused by higher effect of calicum and magnesium ions causing a decrease in SAR of the equilibrating solutions as outlined in table 3 , the decrease in SAR has the effect of causing an apparent increase in KG . Under the studied TEC and SAR range of equilibrating solution, these soils exhibited differential affinity for $\mathrm{Ca}^{2+}$ and $\mathrm{Mg}^{2+}$ or $\mathrm{Na}^{+}$ions . A cursory survey of the literature reveals published $\mathrm{KG}$ values ranging from as low as 0.005 (Jurinak etal.1984) to > 0.03(mmol/l) ${ }^{-0.5}$ (Miller etal.1990; Chaudhari and Somawanshi 2002) . Such variability of KG makes an accurate prediction of the NaX from the SAR measurement difficult unless supporting data are available. This investigation showed that among soil factors influencing the ESR-SAR relationship are . (1) organic matter content which has a high affinity for divalent cations and correspondingly lowering the KG (Haghina and Pratt,1988). (2) Cation exchange capacity where selectivity for $\mathrm{Na}^{+}$decreased as CEC increases (Miller etal.1990). The values of KG obtained in this study especially at Soil- 1 are much lower than the value of $(0.0154 \mathrm{mmol} / \mathrm{l})^{-0.5}$ ( U.S. Salinity Laboratory Staff 1954) and could, in part, be due to the use of the Polemio and Rhoades(1977) method for determining CEC . As outlined in table 1 Soil-1 has higher values of organic matter and cation exchange capacity and accordingly showed lower values for selectivity .(3) the interaction of salinity and clay mineral type is considered a prime factor and may influence CEC and cation preference of the exchanger. The mineralogical analysis results outlined by Fayadh(2007) on selected soils of this study showed that the dominant minerals were Smectite, Illite, Kaolinite , Vermiculite, Palygorkite and the stratified minerals. Despite the fact that the Smectitic minerals were dominant in the studied area, Kaolinite content increased in Soil-2 in addition to Palygorkite which was rare in Soil-1 and common in Soil-2 on the account of Smectite and associated with high calcium carbonate. Kopittke etal.(2006) indicated that for the expanding 2:1 clay minerals, their preference for $\mathrm{Ca}^{2+}$ increased with increasing ionic strength unlike the minerals in which external exchange sites dominated where they show an increase preference for $\mathrm{Na}^{+}$. Correction 
for anion exclusion caused an increase in the values of KG by about $18 \%$ in Soil-1 and $11 \%$ in Soil-2 compared to not corrected samples .

Table (4): The regression equation between ESR corrected for anion exclusion and SAR at various electrolyte concentrations and when the data were handled as a composite.

\begin{tabular}{|c|l|c|}
\hline TEC $\left(\right.$ mmol $\left._{\mathrm{c}} \mathrm{l}^{-1}\right)$ & \multicolumn{1}{|c|}{ Regression equation } & $\mathrm{R}^{2}$ \\
\hline \multicolumn{3}{|c|}{ Soil -1} \\
\hline 5 & $\mathrm{Y}=0.0156+0.0066 \mathrm{X}$ & 0.998 \\
\hline 10 & $\mathrm{Y}=0.0209+0.004 \mathrm{X}$ & 0.978 \\
\hline 20 & $\mathrm{Y}=0.0199+0.0046 \mathrm{X}$ & 0.935 \\
\hline 50 & $\mathrm{Y}=0.0128+0.0053 \mathrm{X}$ & 0.884 \\
\hline 100 & $\mathrm{Y}=0.0131+0.0053 \mathrm{X}$ & 0.935 \\
\hline \multirow{2}{*}{ Composite data } & $\mathrm{Y}=0.0178+0.0048 \mathrm{X}$ (corrected) & 0.919 \\
& $\mathrm{Y}=0.0192+0.0041 \mathrm{X}($ not corrected $)$ & 0.863 \\
\hline \multicolumn{3}{|c|}{ Soil-2 } \\
\hline 5 & $\mathrm{Y}=0.0161+0.0106 \mathrm{X}$ & 0.962 \\
\hline 10 & $\mathrm{Y}=0.0294+0.0095 \mathrm{X}$ & 0.939 \\
\hline 20 & $\mathrm{Y}=0.0363+0.009 \mathrm{X}$ & 0.922 \\
\hline 50 & $\mathrm{Y}=0.0454+0.0098 \mathrm{X}$ & 0.987 \\
\hline 100 & $\mathrm{Y}=0.064+0.0086 \mathrm{X}$ & 0.939 \\
\hline \multirow{2}{*}{ Composite data } & $\mathrm{Y}=0.0284+0.0123 \mathrm{X}($ corrected $)$ & 0.842 \\
& $\mathrm{Y}=0.031+0.0096 \mathrm{X}$ (not corrected) & 0.796 \\
\hline
\end{tabular}

\author{
التفضيل الكاتيوني لترب الفرتيسول \\ عامر وديع عبد الكريم \\ قسم علوم التربة و المو ارد المائية / كلية الزر اعة و الغابات / جامعة الموصل ــ العراق \\ E-mail: amer-waddie@yahoo.com
}

\title{
الخلاصة
}

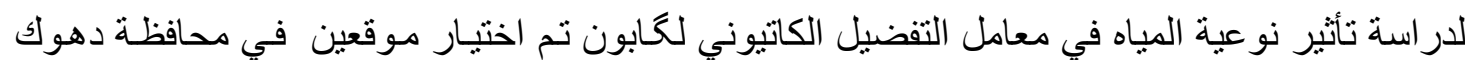

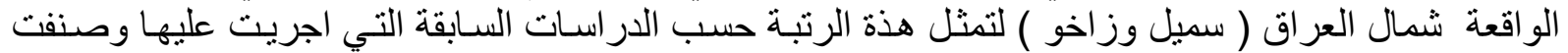

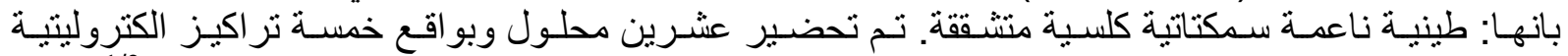

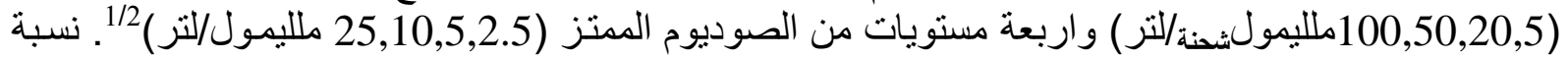

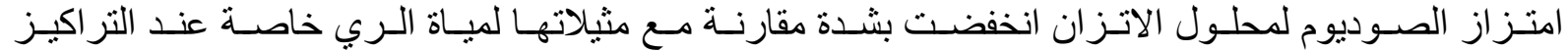

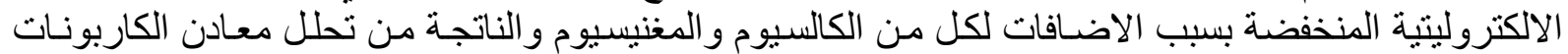

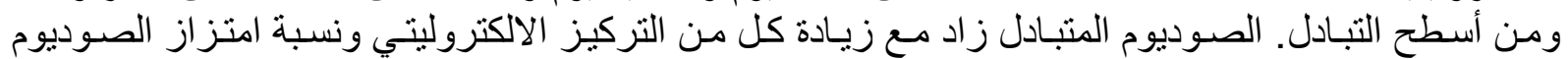

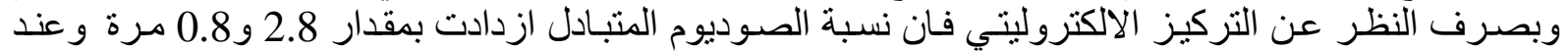

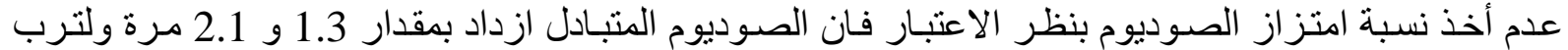

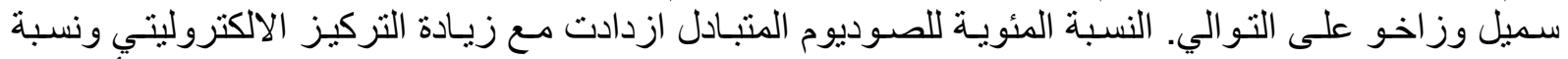

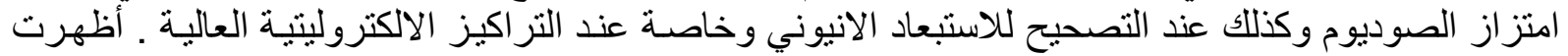

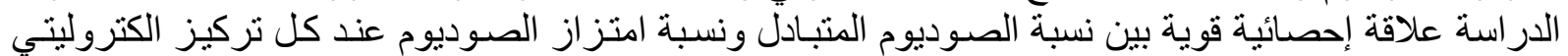

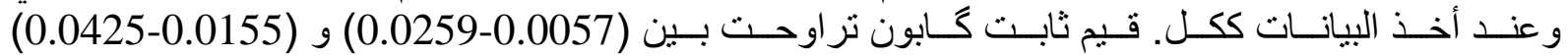


ملليمول /لتر -1/2 والتصحيح للاستبعاد الانيوني سبب زيادة في قيم معامل التفضيل بمقدار 18 و 11\% ولكي ولكل من

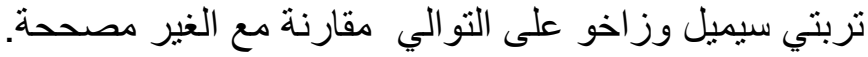

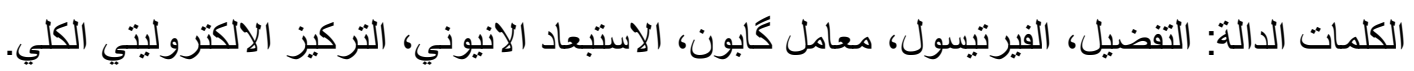
تاريخ تسلم البحث: 2013/2/21 ، وقبوله: 2013/6/24.

\section{REFERENCES}

Ahmad N. and A. Mermut.(1996) . Vertisols and Technologies For Their Management . Development In Soil Science 24. Elsevier, Netherlands.

Amrhein C. and D.L. Suarez (1991). Sodium-Calicum exchange with anion exclusion and weathering corrections . Soil Science Society of American Journal. 55: 698706.

Chaudhari, S.K. and R.B. Somawanshi (2002). Effect of water quality on exchange phase - solution phase behavior of three soils . Journal of Plant Nutrition and Soil Science .165: 229- 234.

Curtin, D .F .Selles and H. Steppuhn (1998). Estimating calcium-magnesium selectivity in smectitic soils from organic matter and texture. Soil Science Society of American Journal , 62: 1280-1285.

Fayadh, M.A.(2007). Characterization and Classification Of Some Vertisols West Of Duhok Governorate .Ph.D. Thesis In Soil and Water Sciences .University of Mosul, Iraq.

Frenkel, H. and N. Alperovitch (1984). The effect of mineral weathering and soil solution concentration on ESR - SAR relationship of arid and semi-arid zone soils from Israel . Journal of Soil Science, 35: 367-372.

Gapon, E.N. (1933) . The electrical double layer and the theory of electro capillarity. Chemistry Review.41:441.

Haghina, G. H. and P.F. Pratt. (1988). Effect of exchangeable magnesium on the accumulation of sodium and potassium in soils . Soil Science, 145:432-436.

Hashim ,F.A.(2011) . Effect Of Irrigation Water Quality On Solid-Liquid Phase Behavior Of Vertisolos in Duhok Governorate .M.Sc. Thesis In Soil and Water Sciences, College of Agriculture, Duhok University, Iraq.

Jurinak.J.J., C. Amrhen and J. Wagenet (1984). Sodic hazard : The effect of SAR and salinity in soils and overburden materials . Soil Science, $137: 152-159$.

Jutzi, S.C., I. Haque, J. Mcintire and J.E.S. Strares (1988) . Management of Vertisolos in sub-saharan Africa .Proceeding Of A Conference Held At ILCA, Addis Ababa, Ethiopia , 92-9053-2.

Kachoui, G.Y., S. R. Ponnia , S.C. Mehta and R. S. Siyag (1994). Sodium-Calcium exchange equilibria in relation to electrolyte concentration and calcium carbonate in soils . Journal of Indian Society of Soil Science, 44: 657-661.

Kopittke , P.M., H.B.So and N.W. Menzies (2006). Effect of ionic strength and clay mineralogy on Na-Ca exchange and the SAR-ESP relationship . European Journal of Soil Science, 57: 626-633. 
Miller, H.P., H. Frenkel, and K.D. Newman. 1990. Flocculation concentration and Sodium-calcium exchange of kaolinitic soil clays . Soil Science Society of American Journal,54:346-351.

Paliwal, K.V. and A.P. Ghandhi (1976). Effect of salinity, SAR, Ca:Mg ratio in irrigation water and soil texture on the predictability of exchangeable sodium percentage . Soil Science, 122:85-90.

Polemio , M. and J.D. Rhoades (1977). Determining cation exchange capacity : A new procedure of calcareous and gypsiferous soils . Soil Science Society of American Journal 41:524-527.

Ponnia, S.R., L.R. Jhorar, J. Nath,S.S. Khanna and A.Singh (1984). Salt balance in soil profiles as affected by different combinations of canal and saline water irrigation . Journal of Research Hissar.4:266-270.

Sharma, O.P. , D.D. Dubey and A.K.. Joshi (1988). Studies on thermodynamic selectivity coefficients in some Vertisolos. Journal of the Indian Society of Soil Science 36: 761-765.

Soil Survey Staff (2006). Keys To Soil Taxonomy . Tenth Edition ,USDA-NRCS.

Tandon, HLS (1999). Methods of Analysis of Soils, Plants, Waters and Fertilizers. Fertilizer Development and Consultation Organization. New Delhi.

U.S. Salinity Laboratory Staff.(1954) . Diagnosis and Improvement Of Saline and Alkali Soils . Agricultural Handbook 60, USDA, Washington ,D.C.

Xu, S. and J. B. Harsh (1990). Monovalent cation selectivity modeled according to hard/soft, acid/base theory. Soil Science Society of American Journal , 45:357363. 